\title{
Effects of Different Harvest Times on the Maturity of Polyphenols in Two Red Wine Grape Cultivars (Vitis vinifera L.) in Qingtongxia (China)
}

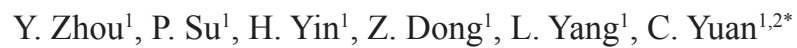 \\ (1) College of Enology, Northwest A\&F University, No. 22 Xinong Rd., Yangling 712100, Shaanxi, China \\ (2) Shaanxi Engineering Research Center for Viti-Viniculture, Yangling 712100, China
}

Key words: Phenolic, ripening, monomer anthocyanins, wines, harvest time

Submitted for publication: December 2017

Accepted for publication: September 2018

\begin{abstract}
Due to the special climate conditions in the Qingtongxia region, grapes are high in sugar and low in titratable acidity from the stages of ripening. Therefore, the common methods used for determining the maturity of grapes, which depend on the ratio of sugar and titratable acidity in other regions, are inappropriate in Qingtongxia. This research was done in order to seek for a simple and convenient method of determining the optimal harvest time of grapes, further providing some theoretical basis for improving the quality of wine in Qingtongxia. Phenolic contents and some basic physico-chemical parameters of Merlot and Pinot Noir were evaluated during different ripening stages. The results showed that a different harvest time significantly affects the phenolic contents and physico-chemical parameters of Merlot and Pinot Noir. The total contents of anthocyanins in skins and total contents of phenolic in seeds was screen out as two important indexes to evaluate the maturity of polyphenols, in order to better improve the quality of grape and wine.
\end{abstract}

\section{INTRODUCTION}

Grapes are cultivated globally, and the quality of the grape is a key factor for the quality of the wines, and the grape maturity significantly affects the quality of grape, thus it is vital to determine appropriate grape maturity during ripening (Kontoudakis et al., 2011; Myunghee et al., 2014; Magariño and José, 2006; Magariño and José, 2013). However, the optimal harvest time is controlled by endogenous numbers and environmental factors including varieties, viticultural technologies, soil, climatic characteristics as well as maturity of grapes (Chira et al., 2009; Condurso et al., 2016; Cook and Wolkovich, 2016; Myunghee et al., 2014).

Total soluble solids ( ${ }^{\circ}$ Brix) and titratable acidity, apart from phenolic content, are the best parameters to use in in the evaluation of grape quality (Conde et al., 2006; Kontoudakis et al., 2011; Ribera-Fonseca et al., 2016; Urraca et al., 2015). However, the content of reduced sugar could not guarantee the best quality of grapes and wines (Conde et al., 2006). The maturity of phenolic, namely 'phenolic maturity' in grapes at harvest time is one of the main factors that affect the quality of the wine (Kontoudakis et al., 2011; Magariño and José, 2006; Rajha et al., 2017). Phenolic compounds are large and complex compounds, which are mainly present in skins and seeds (Obreque-Slier et al., 2010). According to the chemical structure, phenolic compounds can be divided into two groups: flavonoids (flavonols, anthocyanins, flavan-3-ols) and non-flavonoids (cinnamic acid, stilbenes). Therefore, the content of phenolic compounds are the most important quality parameters of grapes and wines (Gil et al., 2012; Lasanta et al., 2014). There was also significant evidence of phenolic compounds affecting the quality of wines and the organoleptic properties, such as the skeleton, structure, colour, the character and quality of wines (Chira et al., 2009; Conde et al., 2006; Garrido and Borges, 2011; Hufnagel and Hofmann, 2008; Martí et al., 2015). However, factors including climate, soil, variety, growth condition, the winemaking process and stages of ripeness affect the content of phenolic compounds (Canals et al., 2005; Cook and Wolkovich, 2016; Intrieri et al., 2010; Jin et al., 2009; Mattivi et al., 2009; Obreque-Slier et al., 2010; ObrequeSlier et al., 2013; Romerocascales et al., 2005; Vilanova et al., 2010). O-Marques et al. (2005) found that ripeness strongly influences the phenolic composition of grape and wines. Previous research reported that insufficiently ripened grapes have a lower extractability of anthocyanins and proanthocyanidins from skins and a higher extractability of proanthocyanidins from seeds, which may produce more astringent and bitter wines (Canals et al., 2005; Peyrot and Kennedy, 2003). However, there is little information available regarding the relationship between the local climatic conditions and phenolic maturity (Sadras and 
Moran, 2012), especially in Northwest China.

Currently, the Northwest wine region of China is popular, and the Qingtongxia wine region is a very important part of it.It is located in arid and semi-arid areas with ideal weather conditions for the growth of grapes, with reasonable light and moderate temperature throughout the year. The soil is mainly sand gravel and grey calcareous clay. Moreover, it belongs to the Yellow River irrigation area, which also makes a big difference. A lot of famous red wine grape varieties including Cabernet Sauvignon, Merlot, and Pinot Noir are cultivated in Qingtongxia. Research has found that the harvest time is strongly related to the kind of wine to be made. In the Qingtongxia region, most of the grapes are used to make aged red wines. Series of studies have reported the relationship between the harvest time of grapes and the quality of wines, which provided a united method to judge the optimal harvest time. However, for the special climatic conditions in Northwest China (Li. et al., 2011), the grapes are affected by several special factors in the process of maturation, with high reducing sugar and low acidity. Few studies have focused on a standard for ensuring the appropriate maturity of grapes in China. The confirmation of the relationship among these factors provided insight into production in this locality. The aim of this study was to find a new way to guide the production practice in the Qingtongxia region. Furthermore, we studied the changes of phenolic compounds in the two red wine grapes during maturation in the years of 2014 and 2015, to determine the optimal harvest time of Pinot Noir and Merlot in Qingtongxia.

\section{MATERIALS AND METHODS}

\section{Experimental design and sample collection}

Pinot Noir and Merlot (Vitis vinifera L. cv.) grape berries were sampled from the experimental vineyard belonging to Yuma in Qingtongxia, Ningxia, China (38.02' N, 106.07' E), at different ripeness stages during 2014 and 2015 vintages. In 2014 and 2015, the highest temperature in Qingtongxia was $35.8^{\circ} \mathrm{C}$ and $35.7^{\circ} \mathrm{C}$, with an average annual temperature of $10.3^{\circ} \mathrm{C}$ and $10.1^{\circ} \mathrm{C}$ (lower than the national average of $14.4^{\circ} \mathrm{C}$ and $14.6^{\circ} \mathrm{C}$ ). An annual total precipitation of 178.5 $\mathrm{mm}$ and $184.6 \mathrm{~mm}$ was found (lower than the national average of $913.6 \mathrm{~mm}$ and $1011.6 \mathrm{~mm}$ ), an annual total sunshine duration of $3086.1 \mathrm{~h}$ and $3181.7 \mathrm{~h}$ (higher than national average of $1991.9 \mathrm{~h}$ and $2408.2 \mathrm{~h}$ ), and lastly, an annual average wind speed of $1.9 \mathrm{~m} / \mathrm{s}$ and $2 \mathrm{~m} / \mathrm{s}$, respectively (data from Ningxia statistical year book of 2014 and 2015). Pinot Noir and Merlot were planted in 2002. The vines were spaced $1.0 \mathrm{~m}$ in row and $3.0 \mathrm{~m}$ between the rows, which were oriented in the North-South direction.

The grapes were harvested at five levels of ripeness, and the first harvest was one week after veraison. The second to fifth harvests were carried out every week form two to five weeks after veraison. The experimental design used the 'Z' method to gather samples. Each sample consisted of 300 berries randomly collected in terms of sun exposure and backlight, the inside and the outside of the cluster, the top, the bottom, and the middle of the cluster. Moreover, it was done one day a week from the beginning of ripeness until harvest. In the last three sampling times, we have harvested another sample of grapes $(20 \mathrm{~kg})$ used for making wines.
These samples were stored at $-20^{\circ} \mathrm{C}$ before use.

Phenolic compounds of grapes in skins and seeds were extracted according to the methods proposed by Di et al. (1991), with minor modifications. They were comprised three independent replicates and each replicate consisted of 30 berries, of which grape skins and seeds were carefully removed using razor blades. Then water and residue on the surface of the grapes were removed and weighed. It was added to $30 \mathrm{~mL}$ of buffer solution $(12 \%(\mathrm{v} / \mathrm{v})$ ethanol $+600 \mathrm{mg} / \mathrm{L}$ sodium metabisulfite $+5 \mathrm{~g} / \mathrm{L}$ tartaric acid, $1 \mathrm{M} \mathrm{NaOH}$ to adjust $\mathrm{pH}$ to 3.20), and put in a swing bed $\left(100 \mathrm{r} / \mathrm{min}, 25^{\circ} \mathrm{C}\right)$. Extraction took place for three days, finally collecting the supernatant, which was also placed in $-20^{\circ} \mathrm{C}$ stored away from light before use.

\section{Determination of the physicochemical indexes of grape berry}

Grape juice was collected and used for assaying reducing sugar and titratable acids, which were analysed according to the methods proposed by OIV (2012).

The tests for total phenolic content (TPC) and total tannin content (TTC) were performed as described by Harbertson et al. (2003) with minor modifications. All buffer solutions were prepared before the experiment. Buffer A was the washing buffer of $200 \mathrm{mM}$ acetic acid and $170 \mathrm{mM}$ sodium chloride, $\mathrm{pH}$ adjusted to 4.9 with sodium hydroxide. Buffer $\mathrm{B}$ was a model wine $(5.0 \mathrm{~g} / \mathrm{L}$ potassium bitartrate and $12 \%$ (v/v) ethanol, $\mathrm{pH}$ adjusted to 3.3 with $\mathrm{HCl}$ ). Buffer $\mathrm{C}$ was a resuspension buffer consisting of $5 \%(\mathrm{v} / \mathrm{v})$ triethanolamine and $5 \%(\mathrm{w} / \mathrm{v})$ sodium dodecyl sulfate, $\mathrm{pH}$ adjusted to 9.4 with $\mathrm{HCl}$. The ferric chloride reagent was $0.01 \mathrm{M} \mathrm{HCl}$ and $10 \mathrm{mM}$ ferric chloride.

For TTC determination, a protein solution for tannin precipitation was prepared by dissolving Bovine serum albumin (BSA) into buffer $\mathrm{A}$, in order to give a final protein concentration of $1.0 \mathrm{mg} / \mathrm{mL}$. The skin extract was diluted with buffer B, $1.0 \mathrm{~mL}$ of the protein solution and $500 \mu \mathrm{L}$ diluted extract of sample $\mathrm{A}$ in a $1.5 \mathrm{~mL}$ microfuge tube. After being incubated for 15 minutes with slow agitation at room temperature, the mixture was centrifuged at 14,000 $\mathrm{g}$ for 5 minutes at $4^{\circ} \mathrm{C}$. After the supernatant was poured out, the residue was washed with buffer $\mathrm{A}$ three times and then resolubilised in $875 \mu \mathrm{L}$ of buffer $\mathrm{C}$. The absorbance of the ferric chloride reagent was added and shaken for 10 minutes. The absorbance of the solution was read at $510 \mathrm{~nm}$ for tannin background $\left(A_{510}\right)$. Then, $125 \mu \mathrm{L}$ of the ferric chloride reagent was added and shook for 10 minutes. The solution was read at $510 \mathrm{~nm}$ for tannin final $\left(A_{510}\right)$. Buffer $\mathrm{C}$ was used as a blank and read at $510 \mathrm{~nm}$ for tannin initial $\left(A_{510}\right)$. After the incubation period, the absorbance at $510 \mathrm{~nm}$ was determined in Shimadzu 640 spectrophotometer using the TEA buffer as a blank. TTC values are reported in catechin equivalents (C.E.) as described here (Harbertson et al., 2003).

For TPC, $20.0 \mu \mathrm{L}$ of wine sample and $855 \mu \mathrm{L}$ of buffer $\mathrm{C}$ were mixed. After incubated for 10 minutes, the mixture was read at $510 \mathrm{~nm}$ (total phenolic background $A_{510}$ ). Then, $855 \mu \mathrm{L}$ of ferric chloride reagent was added into the reaction system. The absorbance was read at $510 \mathrm{~nm}$ (total phenolic final $A_{510}$ ). TPC values are reported in catechin equivalents 
(C.E.) as described bewlow.

The absorbance for TTC $=\left[\left(\operatorname{tannin}\right.\right.$ final $\left.A_{510}\right)-(\operatorname{tannin}$ initial $\left.A_{510}\right)$ ] - (tannin background $\left.A_{510}\right) \times 0.875$. The absorbance for TPC $=\left[\left(\right.\right.$ total phenolic final $\left.A_{510}\right)-($ tannin initial $\left.A_{510}\right)$ ] - (total phenolic background $\left.A_{510}\right) \times 0.875$.

Total flavonoid content (TFC) was determined according to the method of Peinado et al. (2009) with minor modification. In a centrifuge tube, $0.2 \mathrm{~mL}$ of grape extract was added, then, methyl alcohol up until $1.0 \mathrm{~mL}$, then, $2.7 \mathrm{~mL} 30 \%$ methyl alcohol, $0.3 \mathrm{~mL}$ of $\mathrm{NaNO}_{2}(0.5 \mathrm{M})$ and $0.3 \mathrm{~mL}$ of $\mathrm{AlCl}_{3}(0.3 \mathrm{M})$ in this sequence. After 5 minutes, $1.0 \mathrm{~mL}$ of $\mathrm{NaOH}(1.0 \mathrm{M})$ was added to the reaction system. The absorbance was measured against the blank at $510 \mathrm{~nm}$. Results were expressed as rutin equivalents (RE).

Total anthocyanin content (TAC) was estimated using the $\mathrm{pH}$ differential method with minor modification (Lee et al., 2005). Each grape and wine extract was diluted 40 times with buffers at $\mathrm{pH} 1.0$ and 4.5 to attain the same dilution. The absorbance was measured at 520 and $700 \mathrm{~nm}$ in both $\mathrm{pH} 1.0$ and 4.5 buffers. The TAC (expressed in terms of cyanidin-3-glucoside) was calculated using the following formula:

$$
\begin{aligned}
& \mathrm{TAC}=\mathrm{A} \times \mathrm{DF} \times \mathrm{MW} \times 1000 /(\varepsilon \times \mathrm{C}) \\
& \mathrm{A}=\left(A_{520}-A_{700}\right) \mathrm{pH} 1.0-\left(A_{520}-A_{700}\right) \mathrm{pH} 4.5
\end{aligned}
$$

where MW is the molecular weight of cyanidin-3-glucoside (449 $\mathrm{g} / \mathrm{mol}$ ), DF is the dilution factor, $\varepsilon$ is the molar extinction coefficient of cyanidin-3-O-glucoside $(29,600)$, and $\mathrm{C}$ is the concentration of extracted volume.

Total flavanol content was determined according to the method of Li et al. (1996) with minor modification. The grape extract of skins and seeds, including the skin grape extract undiluted and the seed grape extract diluted 5 times, was added with $0.2 \mathrm{~mL}$ of grape extract to the centrifuge tube respectively. Then, mixed with $3 \mathrm{~mL} p$-DMACA solution, after 10 minutes, the absorbance was measured at $640 \mathrm{~nm}$. Results were expressed as catechin equivalents (CE).

\section{Determination the content of monomer anthocyanins}

The chromatographic analyses of anthocyanins were performed using LC-20AT HPLC system (Shimadzu Corporation) equipped with a reversed phase column (Synergi Hydro-RP C18, $250 \times 4.6 \mathrm{~mm}, 4 \mu \mathrm{m}$ ). The mobile phase was ultrapure water, acetonitrile and methanoic acid (800:100:25) as solvent A; and ultrapure water, acetonitrile and methanoic acid (400:500:25) as solvent B. The elution profile had the following proportions $(\mathrm{v} / \mathrm{v})$ of solvent $\mathrm{B}$ : 0.00-15 min, 0\%-10\%; 15-30 min, 10\%-20\%; 30-45 min, $20-35 \%$; 45-46 min, 35\%-100\%; 46.00-50.00 min, 100\%. The column was held at $35^{\circ} \mathrm{C}$ and was flushed at a flow rate of $1 \mathrm{~mL} / \mathrm{min}$. The injection volume was $20 \mu \mathrm{L}$ and analyses were detected at $520 \mathrm{~nm}$.

All phenolic compounds were identified by comparison of their order of elution and retention time with those of standards and the weight of molecular ion, and the fragment ion compared to standards and references. Quantitative determinations were made by using the external standard method compared to the commercial standards. The calibration curves were obtained by injection of standard solutions under the same conditions of the samples analysed. Anthocyanins and flavan-3-ols were expressed respectively as micrograms of malvidin-3-O-glucoside (ME) and catechin equivalence $(\mathrm{CE}) / \mathrm{L}$ of grape skins.

\section{Sensory analysis of wines}

The last three samples were used for making wines. A sensory tasting team was created, made up of 12 people who were trained wine panelists from the College of Enology, Northwest A \& F University (7 females and 5 males, 23-28 years of age). Appearance, aroma, flavor and the overall balance were evaluated according to the tasting table. Finally, statistical analysis was based on the tasting table.

\section{Statistics analysis}

Data were reported as mean \pm standard deviation (SD) values of the triplicate experiments and were analysed using SPSS 24.0 software (IBM Corporation, Armonk, NY, USA). Oneway analysis of variance (ANOVA) and Duncan's multiple range tests (MRT) were used to determine the significance of differences among the means at each sampling time at the significance level of 0.05 . The figures were drawn using the Microsoft Excel 2010.

\section{RESULTS AND DISCUSSION \\ The basic indexes of grapes}

Indexes such as 100 berries' weight, $\mathrm{pH}$ and soluble solids content (SSC) are defined as the technological ripeness of grapes. Table 1 and Table 2 shows the basic indexes of Merlot and Pinot Noir respectively. As expected, most of these indexes presented a rising trend during ripening and showed significant differences between one another $(p \leq 0.05)$. The two tables also showed that the 100 berries' weight presented rising trends at first, and then turned into a downtrend $(p \leq 0.05)$. The SSC, reducing sugar, TA (titratable acidity) and sugar/TA ratio increased regularly during ripening and there was a significant difference among them $(p \leq 0.05)$. These changes kept in line with what Nedomová et al. (2017) previously reported. However, a special phenomenon was that the content of sugar was higher than the standard level, while the content of TA was lower than the standard level during grape ripening, which was different from other reports. It has been found that the climatic characteristics have an innate impact on the harvest time and the quality of the grape, and it can also determine the particular style of the wines in local areas (Cook and Wolkovich, 2016). We inferred that this special phenomenon is caused by the local climate.

The content of reducing sugar varied from $154.62 \pm 2.76$ $\mathrm{g} / \mathrm{L}, \quad 182.17 \pm 0.76 \mathrm{~g} / \mathrm{L}$ to $235.15 \pm 2.73 \mathrm{~g} / \mathrm{L}, 238.87 \pm 1.13$ $\mathrm{g} / \mathrm{L}$; the sugar/TA varied from $16.94 \pm 0.51,19.82 \pm 0.31$ to $40.30 \pm 1.36,42.67 \pm 0.99$; the content of SSC varied from $16.27 \pm 0.15^{\circ}$ Brix, $19.07 \pm 0.12{ }^{\circ}$ Brix to $22.20 \pm 0.001{ }^{\circ} \mathrm{Brix}$, $24.03 \pm 0.05^{\circ} \mathrm{Brix}$, and $\mathrm{pH}$ varied from $3.14 \pm 0.01,3.24 \pm 0.01$ to $3.42 \pm 0.01,3.73 \pm 0.01$ in the grapes of Merlot, both in 2014 and 2015 respectively.

The content of reducing sugar varied from $143.65 \pm 3.10$ $\mathrm{g} / \mathrm{L}, \quad 179.57 \pm 0.74 \mathrm{~g} / \mathrm{L}$ to $232.0 \pm 0.01 \mathrm{~g} / \mathrm{L}, \quad 240.38 \pm 0.66$ $\mathrm{g} / \mathrm{L}$; the sugar/TA varied from $13.48 \pm 0.18,17.94 \pm 0.15$ to $28.89 \pm 0.01,33.47 \pm 0.42$; the content of SSC varied from 


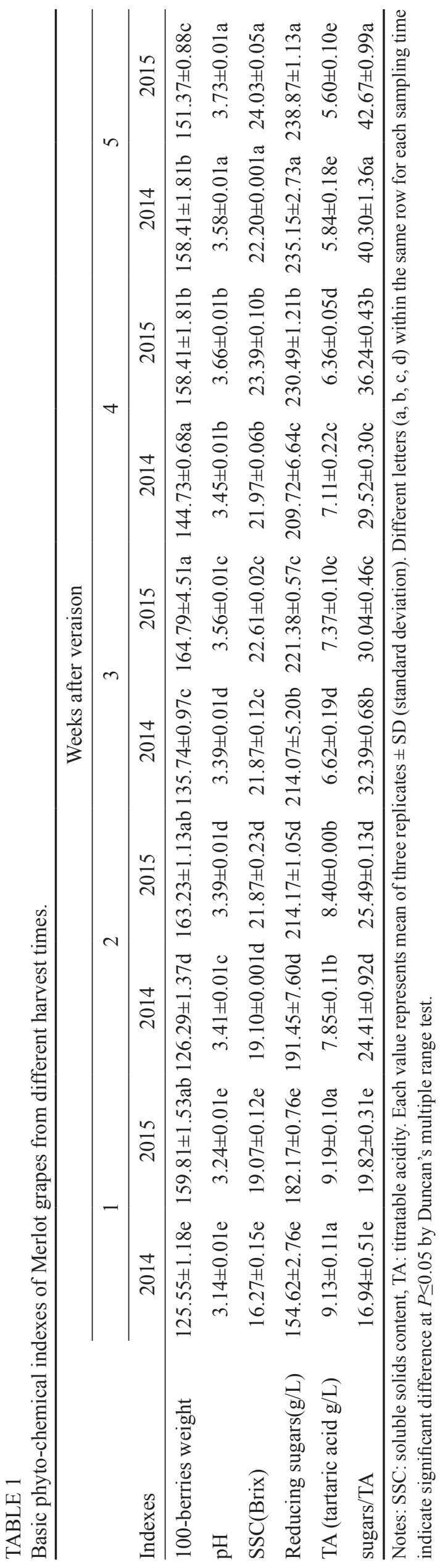

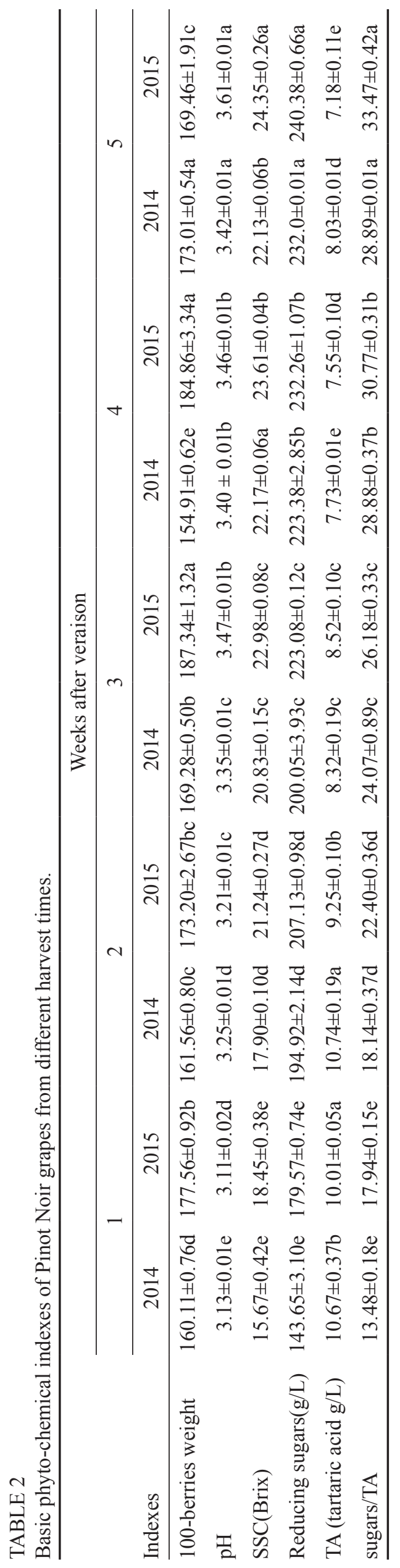

S. Afr. J. Enol. Vitic., Vol. 40, No. 2,2019 
$15.67 \pm 0.42{ }^{\circ} \mathrm{Brix}, 18.45 \pm 0.38{ }^{\circ}$ Brix to $22.13 \pm 0.06{ }^{\circ} \mathrm{Brix}$, $24.35 \pm 0.26^{\circ}$ Brix, and $\mathrm{pH}$ varied from $3.13 \pm 0.01,3.11 \pm 0.02$ to $3.42 \pm 0.01,3.61 \pm 0.01$ in the grapes of Pinot Noir in 2014 and 2015 respectively. The reducing sugars were slightly higher than that of other wine regions and the TA was seriously under the normal standard level. This phenomenon is common in Northwest China, while it is detrimental to the grape production. Furthermore, the phenomenon influences the quality of wines to some extent (Mota et al., 2011). Therefore, increasing the content of TA becomes a crucial technology during vinification. However, there is very little research available about the factors influenced by the harvest time in Northwest China.

According to the OIV, grapes are considered to be ripened when SSC reached the content of $220.00 \mathrm{~g} / \mathrm{L}$. However, as can be seen in Table 1 and Table 2, between three and four weeks after veraison, the SSC content did not show significant difference and reached above of $220.00 \mathrm{~g} / \mathrm{L}$ both for Merlot and Pinot Noir. Therefore, it was difficult to determine the certain harvest time in Northwest China. Meanwhile, due to more sunlight $(262.9 \mathrm{~h}$ and $316.2 \mathrm{~h}$ in August of 2014 and 2015, respectively) and less rainfall (45.9 $\mathrm{mm}$ and $19.9 \mathrm{~mm}$ in August of 2014 and 2015, respectively) during the early ripening in 2015 compared with 2014, higher levels of the basic indexes was found in 2015 than in 2014. However, the relationship between the maturity of polyphenols and the harvest time has not been fully elucidated in Northwest China. Therefore, we concluded that not only the basic indexes should be considered (SSC, reducing sugar and sugar/TA), but also other factors, such as phenolic compounds that affect the quality of wines (Ribera-Fonseca et al., 2016), when determining the most appropriate harvest time.

Notes: SSC: soluble solids content, TA: titratable acidity. Each value represents mean of three replicates \pm SD (standard deviation). Different letters (a, b, c, d) within the same row for each sampling time indicate significant difference at $P \leq 0.05$ by Duncan's multiple range test.

\section{Phenolic compounds of grape berries}

Total contents of polyphenols in the skins and seeds of grapes were determined in Merlot and Pinot Noir at different ripening degrees. As can be seen from Tables 3, 4 and Figures $1,2,3$ and 4 , the different stages of maturity significantly influenced the content of phenolic compounds from different parts.

As shown in Table 3, 4 and Figure 1, 2, 3 and 4, the content of phenolic compounds reached the maximum five weeks after veraison in 2014. However, the content of phenolic compounds attained the maximum three weeks after veraison in 2015. Generally, the content of phenolic compounds in the skins of grapes showed a rising trend during ripening, while these showed a downtrend in the seeds of grapes. However, the content of phenolic compounds showed a similar trend both in skins and seeds of grapes during ripening (Table 3 and 4) five weeks after veraison in 2014. In 2015, three weeks after veraison the content of phenolic compounds were higher compared to before or after this stage. The content of total phenolic compounds, the anthocyanin and the flavonoids in the skins were significantly higher during ripening (Allegro et al., 2016; Fournand et al., 2006). The content of phenolic compounds in the skins of grapes were significantly influenced by the sampling time. Similarity, the total phenolic contents, the anthocyanin and the flavonoids in the seeds showed a downtrend in the continuous two years, entirely. In 2015, the content of total phenolic compounds reached the highest value $(69.34 \pm 1.43 \mathrm{mg} / \mathrm{g})$, the content of anthocyanin reached $7.80 \pm 0.14 \mathrm{mg} / \mathrm{g}$ on August 28 in the skins of Pinot Noir. In Merlot, the content of total phenolic compounds reached the highest value $(32.52 \pm 0.76 \mathrm{mg} / \mathrm{g})$ in the skins and in the seeds $(77.95 \pm 2.30 \mathrm{mg} / \mathrm{g})$ after three and five weeks of veraison, respectively. Furthermore, these indexes showed a higher level in 2015 than in 2014. This might be related to the local climate characterised by more rainfall during ripening in 2014, which would result in the decreased biosynthesis of phenolic compounds. Our results relate well to this trend (Gil et al., 2012; Li et al., 2014; Lorrain et al., 1991).

According to the content of phenolic compounds, including the phenolic compounds in the skins and in the seeds, optimal harvest time could be performed five weeks after veraison in 2014 and three weeks after veraison in 2015. Tt this time the quality of grapes and wines was best, and parts of the sensory analysis of the wines also confirmed the conclusion. A series of literature reported that the content of phenolic compounds and the maturity of the grape have a significant correlation (Bordiga et al., 2011; Obreque-Slier et al., 2013).

Table 3 and 4 showed the content of phenolic compounds, which were medium compared to other wine grape cultivars from different regions (Li. et al., 2011). Principal component analysis (PCA) and correlation analysis displayed that when reducing sugar-acid ratio in order to reach the requirements of harvest, the contents of anthocyanins in skins and the total content of phenolic compounds in seeds were vital for the quality of grapes and wines (Chira et al., 2009; Hernándezhierro et al., 2014).

\section{Determination of the content of monomer anthocyanins in wines}

The anthocyanins in wine are mainly macerated from the peel of grapes, which is crucial for the colour of wines (Bindon et al., 2013; Gil et al., 2012; Magariño and José, 2006; Magariño and José, 2013; Romerocascales et al., 2005). Table 5 and 6 showed the kinds and contents of monomer anthocyanins at different sampling times in Pinot Noir and Merlot. Five kinds of non-acylated anthocyanins were detected in Pinot Noir at different harvest times, and five kinds of non-acylated anthocyanins and four kinds of acylation anthocyanins were detected in Merlot. The anthocyanin content was $63.99 \% \sim 71.41 \%$ in wines. During ripening, there was a variation of monomer anthocyanins in the skins of Pinot Noir and Merlot, which was a significant difference $(p \leq 0.05)$. In 2014 , the content of monomer anthocyanins reached a maximum in the wines of Pinot Noir and Merlot five weeks after veraison, however, these kinds of phenomenon appeared after three weeks of the veraison in 2015. Nine kinds of monomer anthocyanins were detected, in which the content of malvidin-3-O-glucoside are most 


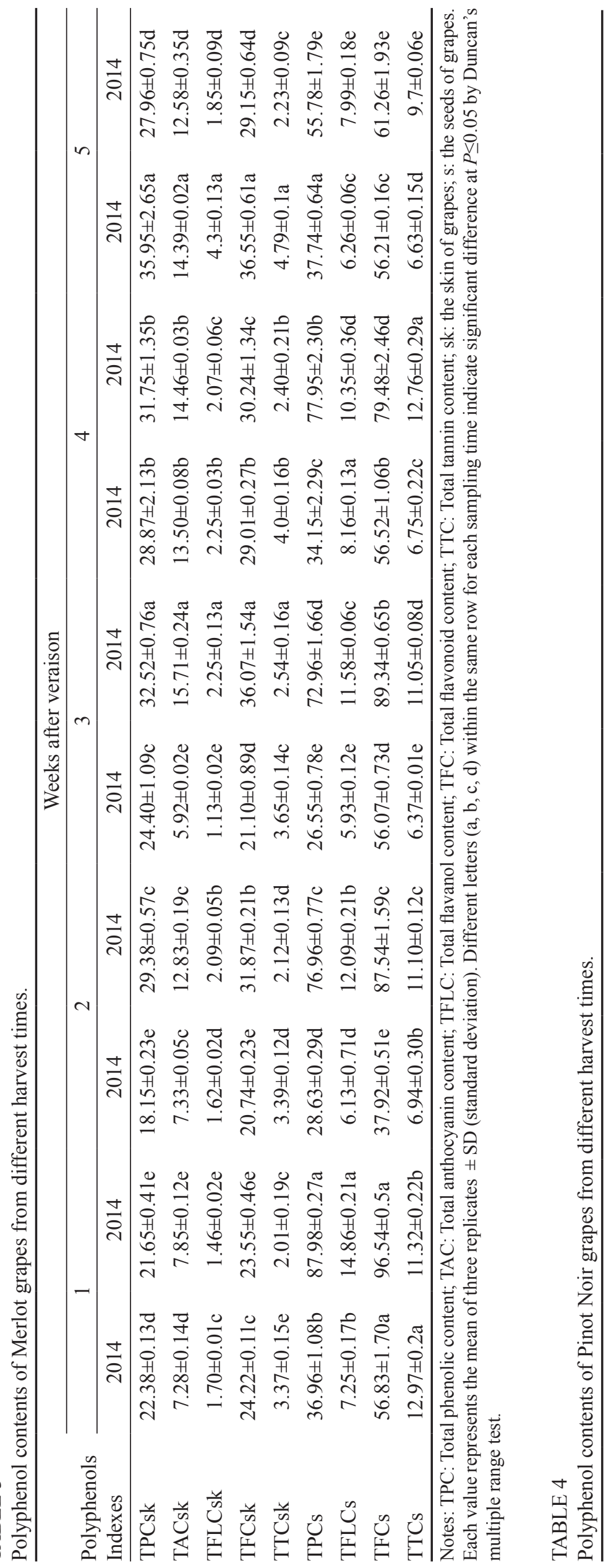

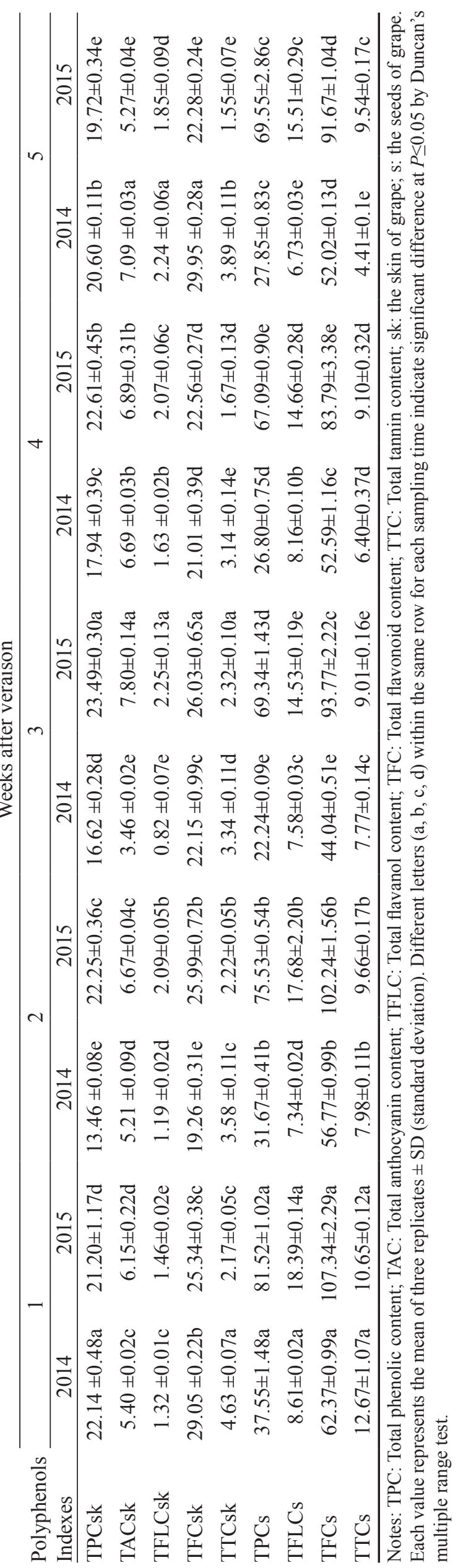



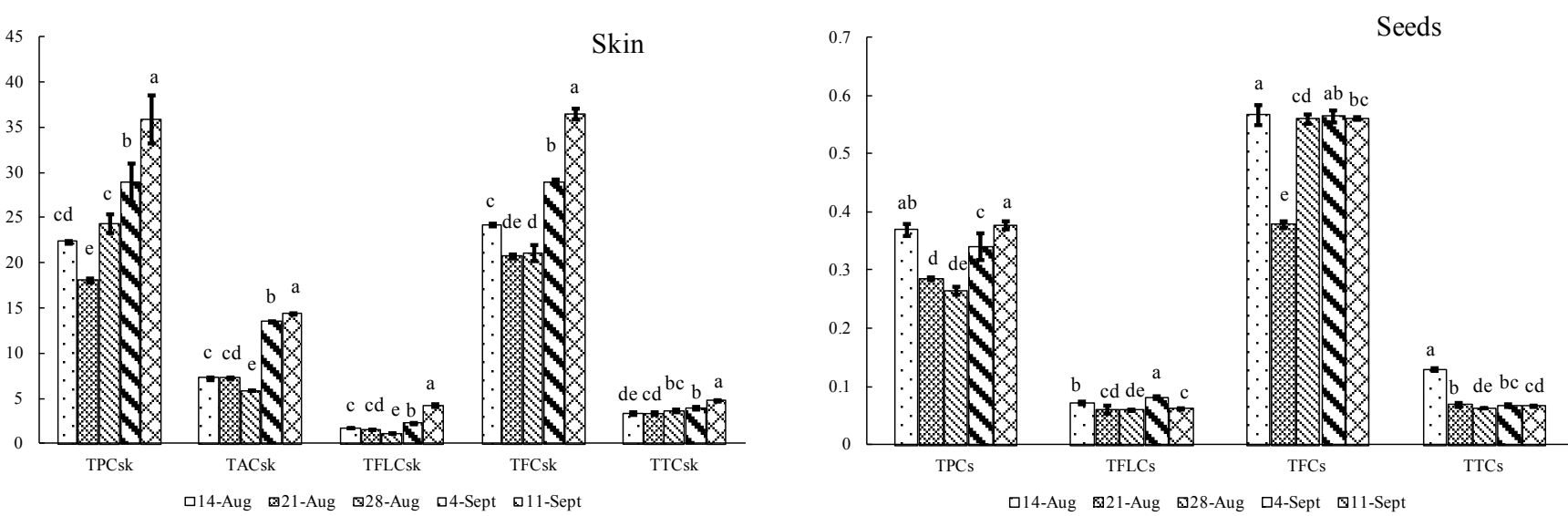

FIGURE 1

Polyphenol indexes of skins and seeds of Merlot grapes at different sampling times in 2014. TPC: Total phenolic content; TAC: Total anthocyanin content; TFLC: Total flavanol content; TFC: Total flavonoid content; TTC: Total tannin content; sk: the skin of grapes; s: the seeds of grapes. Each value represents the mean of three replicates \pm SD (standard deviation). Within each sampling time, the bars with different letters ( $\mathrm{a}, \mathrm{b}, \mathrm{c}, \mathrm{d})$ are significantly different at $P \leq 0.05$ (Duncan's multiple range test).
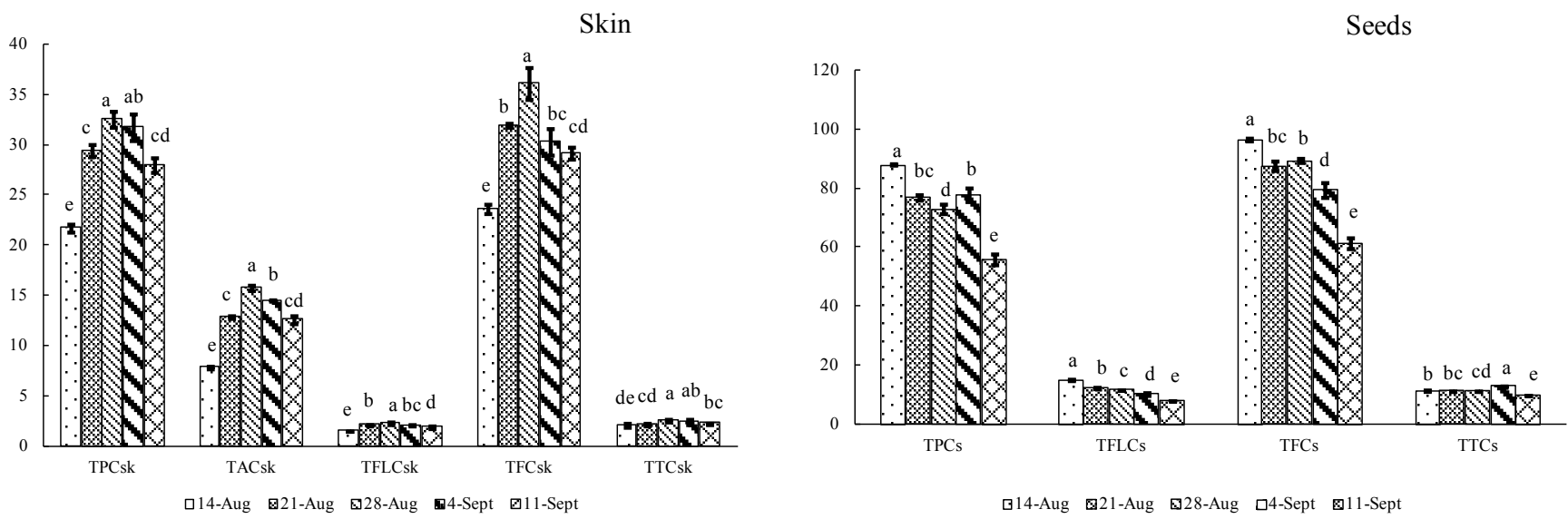

FIGURE 2

Polyphenol indexes of skins and seeds of Merlot grapes at different sampling times in 2015. TPC: Total phenolic content; TAC: Total anthocyanin content; TFLC: Total flavanol content; TFC: Total flavonoid content; TTC: Total tannin content; sk: the skin of grapes; s: the seeds of grapes. Each value represents the mean of three replicates \pm SD (standard deviation). Within each sampling time, the bars with different letters $(\mathrm{a}, \mathrm{b}, \mathrm{c}, \mathrm{d})$ are significantly different at $P \leq 0.05$ (Duncan's multiple range test).

abundant in PW-1, PW-2, and PW-3, indicating that the malvidin-3-O-glucoside was the main substance contribution for colour. Therefore, the colour of wine for the production of premium red wine is very important (Magariño and José, 2006).

Table 5 and 6 showed the content of monomeric anthocyanins in wines at different harvest times. As can be seen, the class of monomeric anthocyanins was the same as that of the berries of grapes in the wines. At the same time, the tables showed malvidin-3-O-glucoside enriched wines; the content reached more than 50 percent of total anthocyanins (Fanzone et al., 2011; Giuffrè, 2013).

The content of monomeric anthocyanins in wines decreased markedly during ripening in 2015, contrary to 2014. The anthocyanin synthesis and content of monomeric anthocyanins were affected by the temperatures, for example, in the cold year (2014), levels were significantly higher than in the hot and dry year (Liang et al., 2012). As indicated in Table 5, the contents of malvidin-3-O-glucoside were highest in MW-3. MW-3 and PW-3 was $122.98 \mathrm{mg} / \mathrm{g}, 114.86 \mathrm{mg} / \mathrm{g}$ respectively, and content of malvidin-3-O-glucoside was relatively low in MW-1 and PW-1, as it was $69.72 \mathrm{mg} / \mathrm{g}$ and $86.22 \mathrm{mg} / \mathrm{g}$ respectively in 2014 .

Contents of malvidin-3-O-glucoside varied from $69.72 \mathrm{mg} / \mathrm{L} \sim 122.98 \mathrm{mg} / \mathrm{L}$ in Merlot, which accounted for $57.3 \% \sim 62.3 \%$ of the total anthocyanins. The contents of total anthocyanins ranged from 121.61 to $197.41 \mathrm{mg} / \mathrm{L}$, in which non-acylated anthocyanins accounted for $76.9 \%$ of total anthocyanins. In MW-3, acylated anthocyanins accounted for $20 \%$ of the wines. In Pinot Noir, the monomeric anthocyanins 

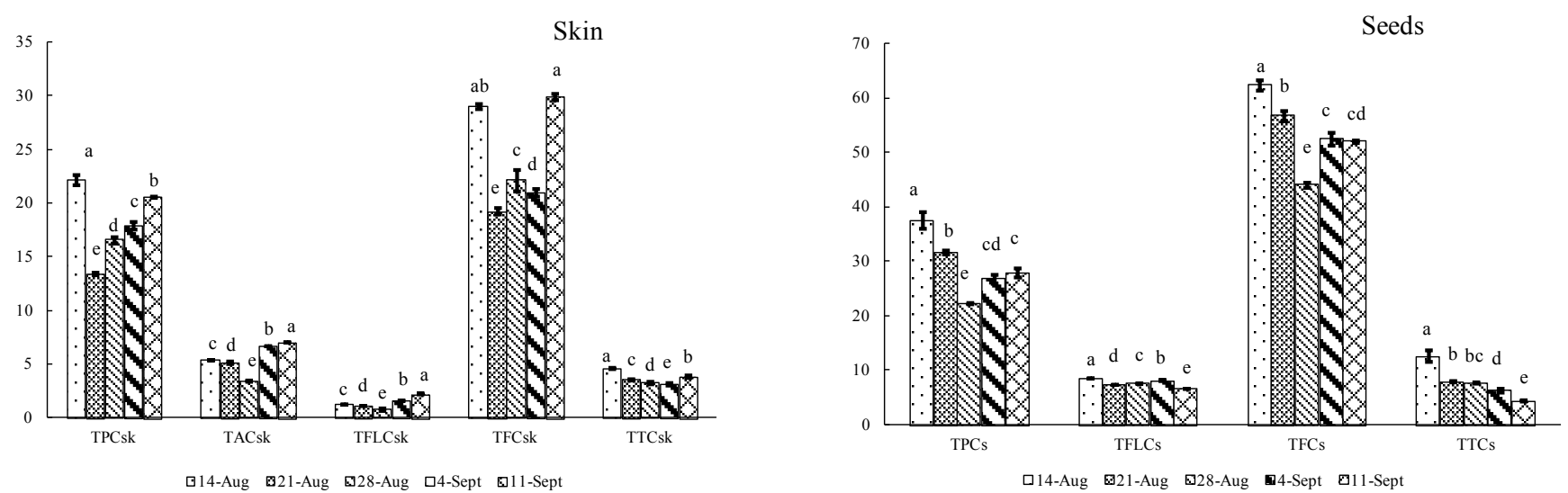

FIGURE 3

Polyphenol indexes of skins and seeds of Pinot Noir grapes at different sampling times in 2014. TPC: Total phenolic content; TAC: Total anthocyanin content; TFLC: Total flavanol content; TFC: Total flavonoid content; TTC: Total tannin content; sk: the skin of grapes; s: the seeds of grapes. Each value represents the mean of three replicates \pm SD (standard deviation). Within each sampling time, the bars with different letters (a, b, $\mathrm{c}, \mathrm{d})$ are significantly different at $P \leq 0.05$ (Duncan's multiple range test).
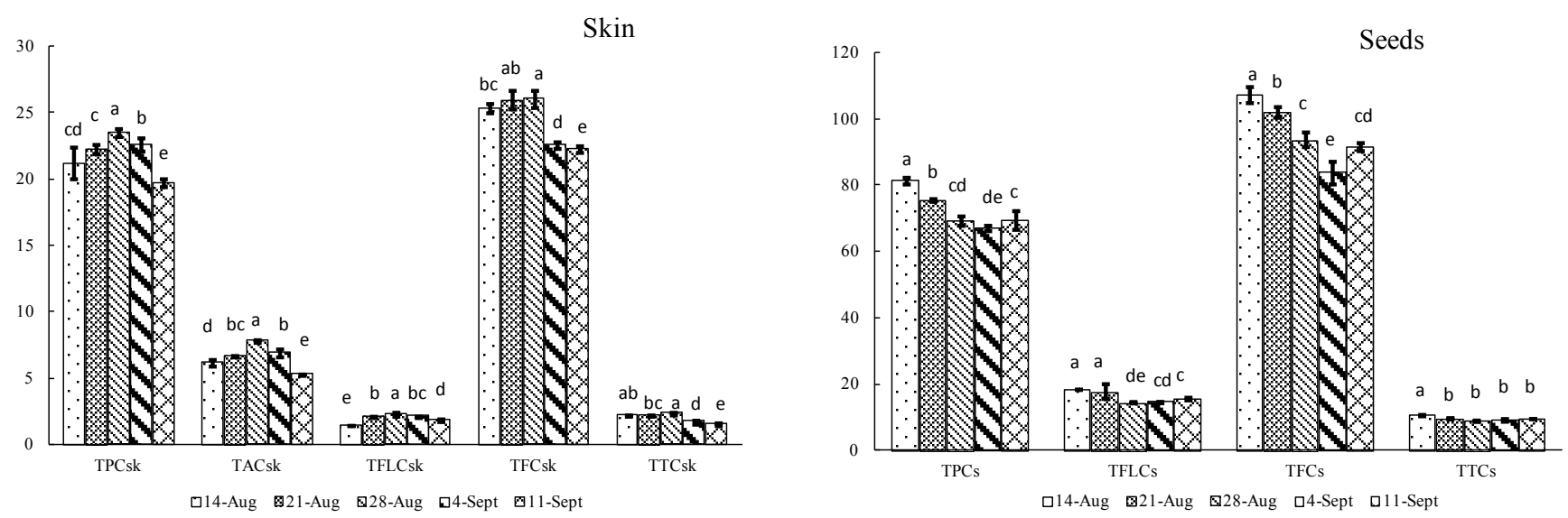

FIGURE 4

Polyphenol indexes of skins and seeds of Pinot Noir grapes at different sampling times in 2015. TPC: Total phenolic content; TAC: Total anthocyanin content; TFLC: Total flavanol content; TFC: Total flavonoid content; TTC: Total tannin content; sk: the skin of grapes; s: the seeds of grapes. Each value represents the mean of three replicates \pm SD (standard deviation). Within each sampling time, the bars with different letters (a, b, c, d) are significantly different at $P \leq$ mean (Duncan's multiple range test).

were non-acylated anthocyanins, and the contents of malvidin-3-O-glucoside were also the maximum, accounting for $90 \%$ of total anthocyanins. As can be seen from Table 5 and 6 , the malvidin-3-O-glucoside was the most abundant monomeric anthocyanin, reaching more than $52 \%$, followed by malvidin-3-O-(6-O-Acetyl)-glucoside, of which the content accounted for $79.47 \% \sim 82.26 \%$ and $82.49 \% \sim 85.49 \%$ of the total content of monomer anthocyanins, respectively. This indicated that both malvidin-3-O-glucoside and malvidin-3-O-(6-O-Acetyl)-glucoside play pivotal roles in the anthocyanin, which makes the colour of the wine (Bindon et al., 2014; Magariño and José, 2013). Furthermore, it was crucially important to control the maturity of the phenolic compounds for the quality of grapes and wines according to the results (Bindon et al., 2013; Bindon et al., 2014; Magariño and José, 2006). Also, the monomer composition and content of anthocyanins were related to the grape varieties (Liang et al., 2008; Segade et al., 2009).

\section{Sensory analysis of wine}

After homogenisation of the tasting data, the data were conducted with Quantitative descriptive analysis (QDA). The results demonstrated that the wines from grapes on the third harvesting times (PW-3) are the best in the continuous two years (Fig.5, 6).

The organoleptic properties of PW-3 wines, including the clarity, flavour preferences and overall balance were the best, followed by PW-2 and PW-1. However, the colour and aroma intensity of wines from PW-2 were the best, 0.94 and 0.90 respectively, followed by PW-3 and PW-1 in 2015. Previous studies have shown that the compounds related to colour and aroma are very important for determining the optimal harvest time (Cadot et al., 2012; Chang et al., 2014). The colour and aroma intensity of the wines from PW-2 was 
TABLE 5

Contents of anthocyanins in wine from different harvest times in 2014.

\begin{tabular}{|c|c|c|c|c|c|c|c|c|c|c|}
\hline \multirow[b]{2}{*}{ Wine simples } & \multicolumn{9}{|c|}{ Free anthocyanins contents in skins(mg/g) } & \multirow[b]{2}{*}{ Total contents } \\
\hline & $\mathrm{Dp}$ & $\mathrm{Cy}$ & $\mathrm{Pt}$ & Pn & $\mathrm{Mv}$ & $\mathrm{Pn}-\mathrm{Ac}$ & $\mathrm{Mv}-\mathrm{Ac}$ & Pt-Co & $\mathrm{Mv}-\mathrm{Co}$ & \\
\hline \multicolumn{11}{|l|}{ Merlot } \\
\hline MW-1 & 7.41 & 1.18 & 10.21 & 6.72 & 69.72 & 3.46 & 17.66 & 4.11 & 1.14 & 121.61 \\
\hline MW-2 & 7.88 & 0.93 & 14.22 & 7.83 & 118.25 & 6.15 & 30.02 & 6.78 & 1.86 & 193.91 \\
\hline MW-3 & 9.83 & 1.23 & 17.05 & 7.74 & 122.98 & 4.41 & 22.88 & 8.84 & 2.51 & 197.46 \\
\hline \multicolumn{11}{|l|}{ Pinot Noir } \\
\hline PW-1 & 1.22 & 0.51 & 3.64 & 4.33 & 86.22 & - & - & - & - & 95.92 \\
\hline PW-2 & 1.58 & 0.26 & 3.99 & 4.22 & 103.44 & - & - & - & - & 113.49 \\
\hline PW-3 & 1.92 & 0.74 & 4.76 & 4.89 & 114.86 & - & - & - & - & 127.17 \\
\hline
\end{tabular}

Notes: Dp: Delphinidin-3-O-glucoside; Cy: Cyanidin-3-O-glucoside; Pt: Petunidin-3-O-glucoside; Pn: Peonidin-3-O-glucoside; Mv: Malvidin-3-O-glucoside; Pn-Ac: Peonidin-3-O-(6-O-Acetyl)-glucoside; Mv-Ac: Malvidin-3-O-(6-O-Acetyl)-glucoside; Pt-Co: Petunidin-3$O$-(6-O-Coumaryl)-glucoside; Mv-Co: Malvidin-3-O-(6-O-Coumaryl)-glucoside; “-”: shows did not check out; MW-1, 2, 3: the wines of Merlot made of grapes harvested on the three, four, and five weeks after veraison, respectively; PW-1, 2, 3: the wines of Pinot Noir made of the grapes harvested on three, four, and five weeks after veraison, respectively.

TABLE 6

Contents of monomer anthocyanins in wines from different harvest times in 2015.

\begin{tabular}{|c|c|c|c|c|c|c|c|c|c|c|}
\hline \multirow[b]{2}{*}{ Wine simples } & \multicolumn{9}{|c|}{ Free anthocyanins contents in skins $(\mathrm{mg} / \mathrm{g})$} & \multirow[b]{2}{*}{ Total contents } \\
\hline & Dp & $\mathrm{Cy}$ & $\mathrm{Pt}$ & $\mathrm{Pn}$ & $\mathrm{Mv}$ & Pn-Ac & $\mathrm{Mv}-\mathrm{Ac}$ & $\mathrm{Pt}-\mathrm{Co}$ & $\mathrm{Mv}-\mathrm{Co}$ & \\
\hline \multicolumn{11}{|l|}{ Merlot } \\
\hline MW-1 & 4.60 & 0.75 & 10.50 & 3.98 & 131.39 & 4.87 & 38.60 & 1.55 & 10.40 & 206.64 \\
\hline MW-2 & 4.98 & 0.87 & 10.94 & 5.63 & 126.38 & 4.30 & 25.94 & 1.78 & 8.57 & 189.39 \\
\hline MW-3 & 4.87 & 0.83 & 10.80 & 6.38 & 114.79 & 3.93 & 19.52 & 1.62 & 6.27 & 169.01 \\
\hline \multicolumn{11}{|l|}{ Pinot Noir } \\
\hline PW-1 & 0.61 & 0.40 & 2.65 & 2.46 & 95.63 & - & - & - & - & 101.75 \\
\hline PW-2 & 0.42 & 0.41 & 2.04 & 1.81 & 94.15 & - & - & - & - & 98.83 \\
\hline PW-3 & 0.38 & 0.40 & 1.84 & 2.16 & 87.61 & - & - & - & - & 92.39 \\
\hline
\end{tabular}

Notes: Dp: Delphinidin-3-O-glucoside; Cy: Cyanidin-3-O-glucoside; Pt: Petunidin-3-O-glucoside; Pn: Peonidin-3-O-glucoside; Mv: Malvidin-3-O-glucoside; Pn-Ac: Peonidin-3-O-(6-O-Acetyl)-glucoside; Mv-Ac: Malvidin-3-O-(6-O-Acetyl)-glucoside; Pt-Co: Petunidin-3$O$-(6-O-Coumaryl)-glucoside; Mv-Co: Malvidin-3-O-(6-O-Coumaryl)-glucoside; “-”: shows did not check out; MW-1, 2, 3: the wines of Merlot made of grapes harvested on three, four, and five weeks after veraison, respectively; PW-1, 2, 3: the wines of Pinot Noir made of the grapes harvested on three, four, and five weeks after veraison, respectively.

lowest, followed by PW-3 and PW-1. Due to the climate changes in 2014, the result was opposite in 2015. The aroma compounds in the grapes are affected by the degree of maturity, climate, variety and other factors (Coelho et al., 2007; Magariño and José, 2006). Only when the grapes reached high-level maturity, we could evaluate the quality of aroma (Coelho et al., 2007; Vilanova et al., 2010). According to the scored points of wines, PW-3 was the best, followed by PW-2 and PW-1.

As for the quality of Merlot, the quality of wines from MW-3 was the best, therefore, the optimal harvest time for
Merlot is five weeks after veraison. However, the taste scores of MW-2 were the highest followed by MW-3 and MW-1, while, in addition to the taste, the other sensory indicators of MW-3 wines were the highest, followed by MW-1 and MW-2.

\section{CONCLUSIONS}

By studying the grapes and wines from different sampling times, a significant relationship was observed between the harvest time and the content of phenolic compounds. Also, at difference sampling times, the basic indexes and the content 

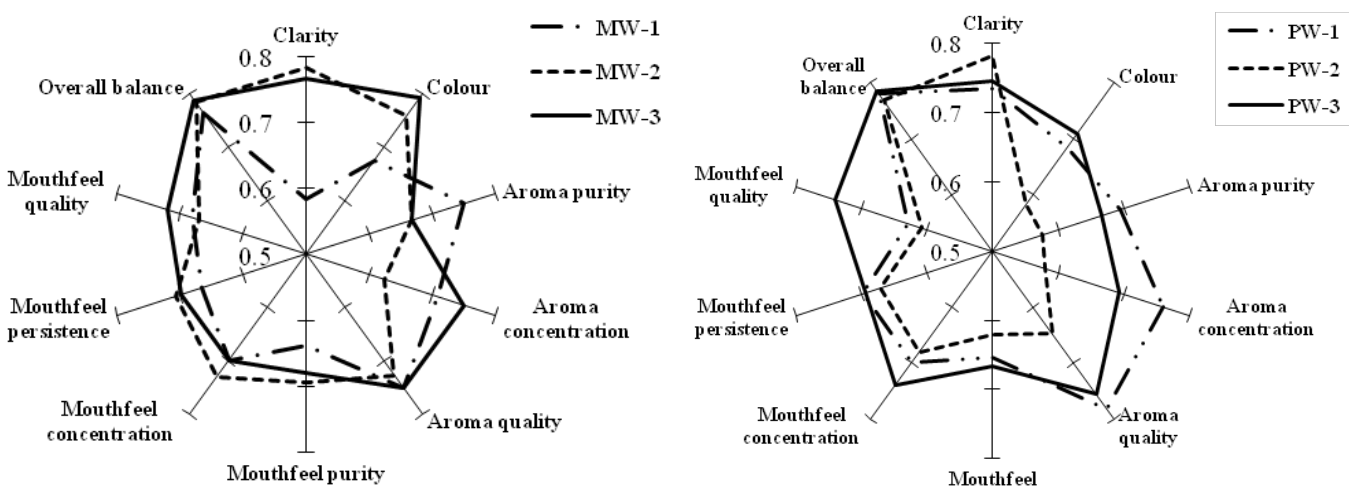

FIGURE 5

The organoleptic properties of wines at different sampling times in 2014. MW-1, 2, 3: the wines made of Merlot grapes harvested on three, four, and five weeks after veraison, respectively; PW-1, 2, 3: the wines made of Pinot Noir grapes harvested on three, four, and five weeks after veraison, respectively.
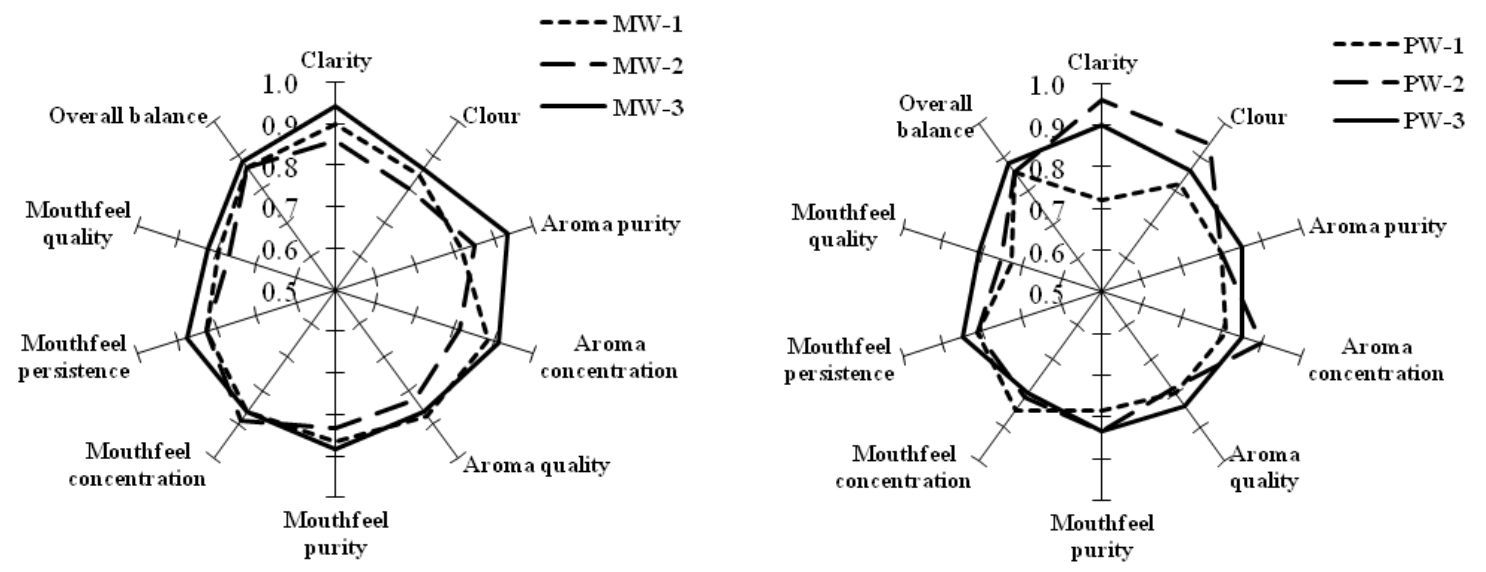

FIGURE 6

The organoleptic properties of wines at different sampling times in 2015. MW-1, 2, 3: the wines made of Merlot grapes harvested on three, four and five weeks after veraison, respectively; PW-1, 2, 3: the wine made of Pinot Noir grapes harvested on three, four, and five weeks after veraison, respectively.

of phenolic compounds of grapes had significant differences. Hence, our data provide support for ensuring the best harvest time. Three and five weeks after veraison of 2014 and 2015, respectively, could be the optimal harvest time from looking at the content of phenolic compounds and from the sensory analysis of wines. Further studies about the relationship between the harvest time and the content of monomer anthocyanins in wines, as well as more sensory analysis of wines will be of greater benefit to determine the optimal harvest time, further to obtain the best quality of wines. On the basis of our findings from this study, we proposed two indexes in order to simplify the practice of winery. The content of anthocyanins in skins and total content of phenolic compounds in seeds are seen as the principal index when the reducing sugar-acid ratio reaches the requirements of harvest. This was done in order to illustrate the optimal harvest time and to ensure the best quality of grapes and wines in the locality. For the special climatic conditions in Northwest China, our conclusion would be a benefit to the quality of wines produced in the locality.

\section{LITERATURE CITED}

Allegro, G., Pastore, C., Valentini, G., Muzzi, E. \& Filippetti, I., 2016. Influence of berry ripeness on accumulation, composition and extractability of skin and seed flavonoids in cv. Sangiovese ( $V$. vinifera $\mathrm{L}$.). J. Sci. Food Agric. 96, 4553-4559.

Bindon, K., Varela, C., Kennedy, J., Holt, H. \& Herderich, M., 2013. Relationships between harvest time and wine composition in Vitis vinifera $\mathrm{L} . \mathrm{cv}$. Cabernet Sauvignon 1. Grape and wine chemistry. Food Chem. 138, 1696.

Bindon, K., Holt, H., Williamson, P.O., Varela, C., Herderich, M. \& Francis, I.L., 2014. Relationships between harvest time and wine composition in Vitis vinifera L. cv. Cabernet Sauvignon 2. Wine sensory properties and consumer preference. Food Chem. 154: 90-101.

Bordiga, M., Travaglia, F., Locatelli, M., Coïsson, J.D. \& Arlorio, M., 2011. Characterisation of polymeric skin and seed proanthocyanidins during ripening in six Vitis vinifera L. cv. Food Chem. 127, 180-187.

Cadot, Y., Caillé, S., Samson, A., Barbeau, G. \& Cheynier, V., 2012. Sensory representation of typicality of Cabernet franc wines related to phenolic composition: impact of ripening stage and maceration time. Analytica Chimica Acta. 732, 91. 
Canals, R., Llaudy, M.C., Valls, J., Canals, J.M. \& Zamora, F., 2005. Influence of ethanol concentration on the extraction of color and phenolic compounds from the skin and seeds of Tempranillo grapes at different stages of ripening. J. Agric. Food Chem. 53, 4019-4025.

Chang, E.H., Jung, S.M. \& Hur, Y.Y., 2014. Changes in the aromatic composition of grape cv. Cheongsoo wine depending on the degree of grape ripening. Food Sci. Biotechnol. 23, 1761-1771.

Chira, K., Schmauch, G., Saucier, C., Fabre, S. \& Teissedre, P.L., 2009. Grape variety effect on proanthocyanidin composition and sensory perception of skin and seed tannin extracts from Bordeaux wine grapes (Cabernet Sauvignon and Merlot) for two consecutive vintages (2006 and 2007).J. Agric. Food Chem. 57, 545-553.

Coelho, E., Rocha, S.M., Barros, A.S., Delgadillo, I. \& Coimbra, M.A., 2007. Screening of variety- and pre-fermentation-related volatile compounds during ripening of white grapes to define their evolution profile. Analytica Chimica Acta. 597, 257-264.

Conde, C., Silva, P., Fontes, N., Dias, A.C.P., Rui, M.T., Sousa, M.J., Agasse, A., Delrot, S. \& Gerós, H., 2006. Biochemical changes throughout grape berry development and fruit and wine quality. Food. 1, 1-22.

Condurso, C., Cincotta, F., Tripodi, G., Sparacio, A., Giglio, D.M.L., Sparla, S. \& Verzera A., 2016. Effects of cluster thinning on wine quality of Syrah cultivar (Vitis vinifera L.). Eur. Food Res. Technol. 242, 1-8.

Cook, B.I. \& Wolkovich, E.M., 2016. Climate change decouples drought from early wine grape harvests in France. Nature Climate Change. 6, pages.

Di, S.R., Carla, C.M. \& Di, S.R., 1991. Rivista Di Viticoltura E Di Enologia. xliv. vol, 37-45.

Fanzone, M., Zamora, F., Jofré, V., Assof, M. \& Peña-Neira, Á., 2011. Phenolic composition of Malbec grape skins and seeds from Valle de Uco (Mendoza, Argentina) during ripening. Effect of cluster thinning. J. Agric. Food Chem. 59, 6120-6136.

Fournand, D., Vicens, A., Sidhoum, L., Souquet, J.M., Moutounet, M. \& Cheynier, V., 2006. Accumulation and extractability of grape skin tannins and anthocyanins at different advanced physiological stages. J. Agric. Food Chem. 54, 7331 .

Garrido, J. \& Borges, F., 2011. Wine and grape polyphenols-A chemical perspective. Food Research International. 44, 3134-3148.

Gil, M., Kontoudakis, N., González, E., Esteruelas, M., Fort, F., Canals, J.M. \& Zamora, F., 2012. Influence of grape maturity and maceration length on color, polyphenolic composition, and polysaccharide content of Cabernet Sauvignon and Tempranillo wines. J. Agric. Food Chem. 60, 7988-8001.

Giuffrè, A.M., 2013. HPLC-DAD detection of changes in phenol content of red berry skins during grape ripening. Eur. Food Res. Technol. 237, 555564.

Harbertson, J.F., Picciotto, E.A. \& Adams, D.O., 2003. Measurement of polymeric pigments in grape berry extracts and wines using a protein precipitation assay combined with bisulfite bleaching. Am. J. Enol. Vitic. 54, 301-306.

Hernándezhierro, J.M., Quijadamorín, N., Martínezlapuente, L., Guadalupe, Z., Ayestarán, B., Rivasgonzalo, J.C. \& Escribanobailón, M.T., 2014. Relationship between skin cell wall composition and anthocyanin extractability of Vitis vinifera L. cv. Tempranillo at different grape ripeness degree. Food Chem. 146, 41 .

Hufnagel, J.C. \& Hofmann, T., 2008. Orosensory-directed identification of astringent mouthfeel and bitter-tasting compounds in red wine. J. Agric. Food Chem. 56, 1376-1386.

Intrieri, C., Filippetti, I., Allegro, G., Centinari, M. \& Poni, S., 2010. Early defoliation (hand vs mechanical) for improved crop control and grape composition in Sangiovese (Vitis vinifera L.). Aust. J. Grape Wine Res. 14, 25 32 .
Jin, Z.M., He, J.J., Bi, H.Q., Cui, X.Y. \& Duan, C.Q., 2009. Phenolic compound profiles in berry skins from nine red wine grape cultivars in northwest China. Molecules. 14, 4922.

Kontoudakis, N., Esteruelas, M., Fort, F., Canals, J.M., De, F.V. \& Zamora, F., 2011. Influence of the heterogeneity of grape phenolic maturity on wine composition and quality. Food Chem. 124, 767-774.

Lasanta, C., Caro, I., Gómez, J., Pérez, L., 2014. The influence of ripeness grade on the composition of musts and wines from Vitis vinifera cv. Tempranillo grown in a warm climate. Food Res. Int. 64, 432-438.

Lee, J., Durst, R.W. \& Wrolstad, R.E., 2005. Determination of total monomeric anthocyanin pigment content of fruit juices, beverages, natural colorants, and wines by the $\mathrm{pH}$ differential method: collaborative study. J. AOAC Int. 88, 1269-1278.

Li, X.X., He, F., Wang, J., Li, Z. \& Pan, Q.H., 2014. Simple rain-shelter cultivation prolongs accumulation period of anthocyanins in wine grape berries. Molecules. 19, 14843-14861.

Li, Y.G., Tanner, G. \& Larkin, P., 1996. The DMACA-HCl Protocol and the threshold proanthocyanidin content for bloat safety in forage legumes. J. Sci. Food Agric. 70, 89-101.

Liang, N.N., He, F., Bi, H.Q., Duan, C.Q., Reeves, M.J. \& Wang, J., 2012. Evolution of flavonols in berry skins of different grape cultivars during ripening and a comparison of two vintages. Eur. Food Res. Technol. 235, $1187-1197$

Liang, Z., Wu, B., Fan, P., Yang, C., Wei, D., Zheng, X., Liu, C. \& Li, S., 2008. Anthocyanin composition and content in grape berry skin in Vitis germplasm. Food Chem. 111, 837-844.

Lorrain, B., Chira, K. \& Teissedre, P.L., 1991. Phenolic composition of Merlot and Cabernet-Sauvignon grapes from Bordeaux vineyard for the 2009-vintage: Comparison to 2006, 2007 and 2008 vintages. Food Chem. $126,1991$.

Martí, N., Lizama, V., Verdú, J.A., Muñoz, N., Aleixandre, J.L. \& Saura, D., 2015. Prediction of phenolic composition of Monastrell and Tempranillo wines: correlation between phenolic content and traditional variables of fruit maturity. Int. J. Food Prop. 18, 465-479.

Mattivi, F., Vrhovsek, U., Masuero, D. \& Trainotti, D., 2009. Differences in the amount and structure of extractable skin and seed tannins amongst red grape varieties. Aust. J. Grape Wine Res. 15, 27-35.

Mota, R.V.D., Favero, A.C., Silva, C.P.C., Purgatto, E., Shiga, T.M. \& Regina, M.D.A., 2011. Wine grape quality of grapevines grown in the Cerrado Ecoregion of Brazil. Int. J. Vine Wine Sci. 45, 101-109.

Myunghee, J., Yonghee, K., Byulhana, L., Yosup, P. \& Heeseung, P., 2014. Fruit quality and harvest time of 'Heukboseok' grape by fruit load. Korean J. Hort. Sci. Technol. 32, 289-295.

Nedomová, Š., Kumbar, V., Pavloušek, P., Pytel, R., Lampíř, L. \& Buchar, J., 2017. Effect of harvest date on composition and geometry of grape berries. Eur. J. Hort. Sci. 82, 21-30.

Obreque-Slier, E., Pena-Neira, A. \& Lopez-Sous, R., 2010. Comparative study of the phenolic composition of seeds and skins from Carmenere and Cabernet Sauvignon grape varieties (Vitis vinifera L.) during ripening. J. Agric. Food Chem. 58, 3591-3599.

Obreque-Slier, E., Peña-Neira, Á., López-Solís, R., Cáceres-Mella, A., Toledo-Araya, H. \& López-Rivera, A., 2013. Phenolic composition of skins from four Carmenet grape varieties (Vitis vinifera L.) during ripening. Food Sci. Technol. 54, 404-413.

O-Marques, J., Reguinga, R., Laureano, O. \& Ricardo-Da-Silva, J.M., 2005. Changes in grape seed, skin and pulp condensed tannins during berry ripening: effect of fruit pruning. Ciência E Técnica Vitivinícola. 20, 35-52. 
Peinado, J., Lerma, N.L.D., Moreno, J. \& Peinado, R.A., 2009. Antioxidant activity of different phenolics fractions isolated in must from Pedro Ximenez grapes at different stages of the off-vine drying process. Food Chem. 114, 1050-1055.

Peyrot, D.G.C. \& Kennedy, J.A., 2003. Direct method for determining seed and skin proanthocyanidin extraction into red wine. J. Agric. Food Chem. 51, 5877-5881.

Rajha, H.N., Darra, N.E., Kantar, S.E., Hobaika, Z., Louka, N. \& Maroun, R.G., 2017. A comparative study of the phenolic and technological maturities of red grapes grown in Lebanon. Antioxidants.

Ribera-Fonseca, A., Noferini, M., Jorquera-Fontena, E. \& Rombolà, A.D., 2016. Assessment of technological maturity parameters and anthocyanins in berries of cv. Sangiovese (Vitis vinifera L.) by a portable vis/NIR device. Scientia Horticulturae. Vol no.229-235.

Romerocascales, I., Ortegaregules, A., Lopezroca, J.M., Fernandezfernandez, J.I. \& Gomezplaza, E., 2005. Differences in anthocyanin extractability from grapes to wines according to variety. Am. J. Enol. Vitic. 56, 212-219.
Sadras, V.O. \& Moran, M.A., 2012. Elevated temperature decouples anthocyanins and sugars in berries of Shiraz and Cabernet Franc. Aust. J. Grape Wine Res. 18, 115-122.

Segade, S.R., Vázquez, E.S. \& Losada, E.D., 2009. Influence of ripeness grade on accumulation and extractability of grape skin anthocyanins in different cultivars. J. Food Comp. Anal. 21, 599-607.

Urraca, R., Sanz-Garcia, A., Tardaguila, J. \& Diago, M.P., 2015. Estimation of total soluble solids in grape berries using a hand-held NIR spectrometer under field conditions. J. Sci. Food Agric. 96, 3007-3016.

Vilanova, M., Zamuz, S., Vilariño, F. \& Sieiro, C., 2010. Effect of terroir on the volatiles of Vitis vinifera cv. Albariño. J. Sci. Food Agric. 87, 12521256.

Z, L., Q, P., Z, J., L, M. \& C, D., 2011. Comparison on phenolic compounds in Vitis vinifera cv. Cabernet Sauvignon wines from five wine-growing regions in China. Food Chem. 125, 77-83. 